\title{
Operational Efficiency Forecasting Model of an Existing Underground Mine Using Grey System Theory and Stochastic Diffusion Processes
}

\author{
Svetlana Strbac Savic, ${ }^{1}$ Jasmina Nedeljkovic Ostojic, ${ }^{2}$ Zoran Gligoric, ${ }^{3}$ \\ Cedomir Cvijovic, ${ }^{2}$ and Snezana Aleksandrovic ${ }^{3}$ \\ ${ }^{1}$ The School of Electrical and Computer Engineering of Applied Studies, Vojvode Stepe 283, 11000 Belgrade, Serbia \\ ${ }^{2}$ Belgrade University College of Applied Studies in Civil Engineering and Geodesy, Department of Geodesy, Hajduk Stanka 2, \\ 11000 Belgrade, Serbia \\ ${ }^{3}$ Faculty of Mining and Geology, University of Belgrade, Djusina 7, 11000 Belgrade, Serbia
}

Correspondence should be addressed to Svetlana Strbac Savic; svetlanas@viser.edu.rs

Received 3 August 2015; Revised 28 October 2015; Accepted 29 October 2015

Academic Editor: Paolo Maria Mariano

Copyright (C) 2015 Svetlana Strbac Savic et al. This is an open access article distributed under the Creative Commons Attribution License, which permits unrestricted use, distribution, and reproduction in any medium, provided the original work is properly cited.

\begin{abstract}
Forecasting the operational efficiency of an existing underground mine plays an important role in strategic planning of production. Degree of Operating Leverage (DOL) is used to express the operational efficiency of production. The forecasting model should be able to involve common time horizon, taking the characteristics of the input variables that directly affect the value of DOL. Changes in the magnitude of any input variable change the value of DOL. To establish the relationship describing the way of changing we applied multivariable grey modeling. Established time sequence multivariable response formula is also used to forecast the future values of operating leverage. Operational efficiency of production is often associated with diverse sources of uncertainties. Incorporation of these uncertainties into multivariable forecasting model enables mining company to survive in today's competitive environment. Simulation of mean reversion process and geometric Brownian motion is used to describe the stochastic diffusion nature of metal price, as a key element of revenues, and production costs, respectively. By simulating a forecasting model, we imitate its action in order to measure its response to different inputs. The final result of simulation process is the expected value of DOL for every year of defined time horizon.
\end{abstract}

\section{Introduction}

Efficiency is a prerequisite for the survival of every mining company, especially in high competitive market environment such as mineral resource industry. Efficiency signifies company's ability to meet its short or long-term goals. Operational efficiency is defined as the ratio between the input required to run production process and the output gained from the production. In the context of mining business, operational efficiency refers to the length of time until mineral assets are transformed to money. Peak operational efficiency occurs when the right combination of mineral deposit characteristics, human resources, mining technology, and mineral processing come together to optimize mining performance.
Operational efficiency is related to finding the very best way of mining to produce a mineral asset. It enables management of the mining company to increase productivity, increase profitability, improve competitiveness, use freed-up capacity, and enable company to grow or increase its future market value.

Mining company's management uses different strategies to reach their defined goals. One of the most important elements of a company's management operations is to forecast what goals are realistic and capability estimation of the company in order to achieve them. Planners try to forecast the behavior of the input variables of production environment and arrive at desirable states. They create their strategies on realistic targets drawn from these forecasts. A forecast 
is based on past and current production indicators, that is, business numbers. In many cases, the forecast might be burdened by some inaccuracies, so it would be a mistake to base a budget on that. It is very important to emphasize the forecasting acts serve as a basis for further planning.

The forecasting process is performed in a specific environment. If we take into consideration the fact that the environment is changed over time then it is obvious that the forecasts and targets are changed as well. Management must be able to describe environment changes in order to strategically link the forecasting and planning functions, improving the performance of both.

Large capital intensive projects, such as those in the mineral resource industry, are often associated with diverse sources of both endogenous and exogenous uncertainties. These uncertainties can greatly influence the operational efficiency. Having the ability to plan for these uncertainties is increasingly recognized as critical to long-term mining company success. In the mining industry in particular, the relationships between input variables that are controllable and those that are not and the physical and economic outcomes are complex and often nonlinear. Operational efficiency forecasting of mine in today's environment is much complex than it was just a few years ago. There are typically many variables, which are directly or indirectly associated with the forecasting process.

There is a considerable literature dedicated to the operational efficiency measurement. It includes many approaches, which take into account various aspects of the problem.

Briciu et al. [1] applied the concept of Cost-VolumeProfit analysis in monitoring and measuring the performance of companies in the mining industry in Romania. Zhao et al. [2] evaluated operating efficiency of Chinese Coal Mining Companies by Malmqusit Productivity Index. Factor analysis was employed by $\mathrm{Li}$ et al. to evaluate performance of coal mine companies [3]. Four types of empirical tests have been performed (parametric mean differences, nonparametric Wilcoxon rank sum test, static regression panel estimation, and dynamic regression panel estimation) to estimate managerial and operational efficiency of privatized mining companies in Jordan [4]. A stochastic frontier analysis method was used to estimate profit efficiency in the South African mining sector [5]. The analytic hierarchy process (AHP) methodology was selected for ranking the efficiency of selected platinum mining methods [6]. Improving the efficiency of truck/shovel operations can increase the total operational efficiency of mine. To make the truck and shovel fleet more optimum on the basis of productivity improvements and associated costs reduction, it was essential to calculate the best match factors and truck/shovels assignments (or fleet size) for the system [7].

This paper investigates the relationship between ore production rate, fixed costs, revenues, production costs, working days, and degree of use of production capacity, as input variables, and Degree of Operating Leverage (DOL) as indicator of operational efficiency of an existing underground mine. Multivariable grey model is used to establish the time sequence response formula of DOL. This formula enables us to predict the future values of DOL time series based only on a set of the most recent data. To decrease uncertainty of future values of the operational efficiency we use expert's knowledge and simulation processes to find future values of input variables affecting them. Estimation of future revenues is based on the application of mean reversion process, normal and uniform distribution. Geometric Brownian motion is used to define future values of production costs. Values of ore production rate, fixed costs, working days, and degree of use of production capacity are estimated by expert's knowledge.

By simulating a forecasting system, we imitate its action in order to measure its response (output) to different inputs. The simulation allows analysts to describe the uncertainty of variables that influence the value of DOL by different time depending scenarios. The first objective of the use of simulation in the forecasting is to determine the distribution of the DOL from the variables that affect his performance, which results in the average or expected value of DOL for every year of defined time horizon.

\section{Grey Information Systems and Multivariable Grey Model GM(h, N)}

The grey theory established by Dr. Deng includes grey relational analysis, grey modeling, prediction, and decision making of a system in which the model is unsure or the information is incomplete [8]. It provides an efficient solution to the uncertainty, multi-input, and discrete data problem.

Grey models predict the future values of a time series based only on a set of the most recent data depending on the window size of the predictor. It is assumed that all data values to be used in grey models are positive, and the sampling frequency of the time series is fixed. From the simplest point of view, grey models can be viewed as curve fitting approaches [9].

In grey system theory, multivariable grey model (GM $(h$, $N)$ ) denotes a grey model, where $h$ is the order of the differential equation and $N$ is the number of variables. The $\operatorname{GM}(h$, $N)$ is defined as follows [10]:

$$
\sum_{i=0}^{h} a_{i} \frac{d^{(i)} x_{1}^{(1)}(k)}{d t^{(i)}}=\sum_{j=2}^{N} b_{j} x_{j}^{(1)}(k), \quad k=1,2, \ldots, n
$$

where $a_{i}$ and $b_{j}$ are determined coefficients, $x_{1}^{(1)}(k)$ is the major sequence factor, $x_{j}^{(1)}(k)$ is the influencing sequence factors, and $k$ is the time sequence variable.

In this paper we are applying $\operatorname{GM}(1, N)$ [11-15]. First we separate the data into two sequences: major sequence factor (it masters the system behaviors) and influencing sequence factors (it influences the system behaviors).

The major sequence factor is represented as follows:

$$
X_{1}^{(0)}=\left[x_{1}^{(0)}(1), x_{1}^{(0)}(2), \ldots, x_{1}^{(0)}(k)\right]
$$

$$
k=1,2, \ldots, n .
$$


The influence sequence factors are

$$
\begin{gathered}
X_{2}^{(0)}=\left[x_{2}^{(0)}(1), x_{2}^{(0)}(2), \ldots, x_{2}^{(0)}(k)\right], \\
X_{3}^{(0)}=\left[x_{3}^{(0)}(1), x_{3}^{(0)}(2), \ldots, x_{3}^{(0)}(k)\right], \\
\vdots \\
X_{N}^{(0)}=\left[x_{N}^{(0)}(1), x_{N}^{(0)}(2), \ldots, x_{N}^{(0)}(k)\right] .
\end{gathered}
$$

Assume the original series of data with $k$ equal time samples is represented as $X^{(0)}(k)=\left[x^{(0)}(1), x^{(0)}(2), \ldots, x^{(0)}(k)\right], k=$ $1,2, \ldots, n$. The first-order Accumulating Generation Operator $(\mathrm{AGO})$ of $X^{(0)}$ is defined as $X^{(1)}(k)=\left[x^{(1)}(1), x^{(1)}(2)\right.$, $\left.\ldots, x^{(1)}(k)\right]$, where $x^{(1)}(k)=\sum_{k=1}^{n} x^{(0)}(k)$ for $k=1,2, \ldots, n$. This operator is used to smooth the randomness of the data and to weaken the tendency of variation. The average generation of adjacent sample sequence of $X^{(1)}(k)$ is as follows: $Z^{(1)}(k)=\left[z^{(1)}(1), z^{(1)}(2), \ldots, z^{(1)}(k)\right]$, where $z^{(1)}(k)=$ $(1 / 2)\left(x^{(1)}(k)+x^{(1)}(k-1)\right)$, for $k=1,2, \ldots, n$.

The first-order grey differential equation of the $\operatorname{GM}(1, N)$ is

$$
\frac{d x_{1}^{(1)}(k)}{d k}+a x_{1}^{(1)}(k)=\sum_{j=2}^{N} b_{j} x_{j}^{(1)}(k) .
$$

According to the $\mathrm{GM}(1, N)$, the constructed AGO sequence is

$$
x_{1}^{(0)}(k)+a z_{1}^{(1)}(k)=\sum_{j=2}^{N} b_{j} z_{j}^{(1)}(k) .
$$

The constructed AGO sequence can be represented by the following matrix form:

$$
\begin{aligned}
& {\left[\begin{array}{cc}
x_{1}^{(0)} & (2) \\
x_{1}^{(0)} & (3) \\
\vdots \\
x_{1}^{(0)}(n)
\end{array}\right]} \\
& =\left[\begin{array}{cccc}
-z_{1}^{(1)}(2) & x_{2}^{(1)}(2) & \cdots & x_{N}^{(1)}(2) \\
-z_{1}^{(1)}(3) & x_{2}^{(1)}(3) & \cdots & x_{N}^{(1)}(3) \\
\vdots & \vdots & & \vdots \\
-z_{1}^{(1)}(n) & x_{2}^{(1)}(n) & \cdots & x_{N}^{(1)}(n)
\end{array}\right]\left[\begin{array}{c}
a \\
b_{2} \\
\vdots \\
b_{N}
\end{array}\right] .
\end{aligned}
$$

Factors of the matrix $\widehat{a}=\left[a, b_{2}, \ldots, b_{N}\right]^{T}$ are obtained by using the least square method as follows:

$$
\widehat{a}=\left(B^{T} B\right)^{-1} B^{T} Y,
$$

where

$$
\begin{aligned}
Y & =\left[\begin{array}{c}
x_{1}^{(0)}(2) \\
x_{1}^{(0)}(3) \\
\vdots \\
x_{1}^{(0)}(n)
\end{array}\right], \\
B & =\left[\begin{array}{cccc}
-z_{1}^{(1)}(2) & x_{2}^{(1)}(2) & \cdots & x_{N}^{(1)}(2) \\
-z_{1}^{(1)}(3) & x_{2}^{(1)}(3) & \cdots & x_{N}^{(1)}(3) \\
\vdots & \vdots & & \vdots \\
-z_{1}^{(1)}(n) & x_{2}^{(1)}(n) & \cdots & x_{N}^{(1)}(n)
\end{array}\right] .
\end{aligned}
$$

Finally, the $\operatorname{GM}(1, N)$ can be expressed as follows:

$$
\frac{d x_{1}^{(1)}}{d k}+a x_{1}^{(1)}=b_{2} x_{2}^{(1)}+b_{3} x_{3}^{(1)}+\cdots+b_{N} x_{N}^{(1)} .
$$

The time sequence response formula, that is, the solution of (9), is

$$
\begin{aligned}
& \widehat{x}_{1}^{(1)}(k+1)=\left\{x_{1}^{(0)}(1)-\sum_{j=2}^{N} \frac{b_{j-1}}{a} \cdot x_{j}^{(1)}(k+1)\right\} e^{-a k} \\
&+\sum_{j=2}^{N} \frac{b_{j-1}}{a} \cdot x_{j}^{(1)}(k+1), \\
& k=0,1,2, \ldots, n-1 .
\end{aligned}
$$

According to (10), we can obtain $\widehat{X}^{(1)}(k+1)=\left[\widehat{x}_{1}^{(1)}(k+1)\right]$. The fitting forecast value of $x_{k}^{(0)}$ can be obtained by the inverse AGO as follows:

$$
\begin{aligned}
& \hat{x}^{(0)}(k)=\widehat{x}^{(1)}(k)-\widehat{x}^{(1)}(k-1), \quad k=2,3, \ldots, n, \\
& \widehat{x}^{(0)}(1)=x^{(0)}(1), \quad k=0 .
\end{aligned}
$$

The predicted values when $k \leq n$ can be used to check the adequacy of the model and predicted value when $k>n$ can be used as the forecast value for the data series.

The relative percentage error $(\operatorname{RPE}(j, k))$ and the average relative percentage error $\operatorname{ARPE}(j, k))$ are as follows:

$$
\begin{aligned}
\mathrm{RPE} & =\frac{\left|\widehat{x}_{j}^{(0)}(k)-x_{j}^{(0)}(k)\right|}{x_{j}^{(0)}(k)} \times 100 \% \\
\mathrm{ARPE} & =\frac{1}{n-1} \sum_{k=2}^{n} \frac{\left|\widehat{x}_{j}^{(0)}(k)-x_{j}^{(0)}(k)\right|}{x_{j}^{(0)}(k)} \times 100 \% .
\end{aligned}
$$


Grey relational (relevance) analysis is part of grey system theory that gives us information about the relevance degree of each input variable in the system. It is utilized to ascertain the primary factors that are needed to make a superiority comparison in the system [11]. The fundamental principle is to recognize the relevance degree among many factors, according to the similarity levels of the geometrical patterns of sequence curves. We can judge whether they are close or not according to the similar degree of sequence curve shape. The more similar the curve is, the higher the correlation degree between relative series is, and vice versa [11].

Set the major sequence factor variable to be analyzed, $X_{1}^{0}(k), k=1,2, \ldots, n$, as the dependent variable, and the influencing sequence factors, $X_{j}^{0}(k), j=2, \ldots, N$, as the independent variables. Because various variables have different physical significances, that is, dimensions, it is difficult to obtain accurate conclusion. To eliminate dimensions from analysis, equalization method is used, and formula is

$$
x_{j}^{\prime}(k)=\frac{x_{j}(k)}{\sum_{j=1}^{N} x_{j}(k)}, \quad j=1,2, \ldots, N .
$$

The grey relational coefficient is calculated as follows [16]:

$$
\begin{array}{r}
\xi_{j}(k) \\
=\frac{\underbrace{\min }_{j(k)}\left|x_{1}^{\prime}(k)-x_{j}^{\prime}(k)\right|+\theta \cdot \underbrace{\max }_{j(k)}\left|x_{1}^{\prime}(k)-x_{j}^{\prime}(k)\right|}{\Delta_{j}(k)+\theta \cdot \underbrace{\max }_{j(k)}\left|x_{1}^{\prime}(k)-x_{j}^{\prime}(k)\right|}, \\
j=2,3, \ldots, N,
\end{array}
$$

where $\theta$ refers to the discriminating coefficient and $\theta \in[0,1]$; $\Delta_{j}(k)=\left|x_{1}^{\prime}(k)-x_{j}^{\prime}(k)\right|$.

The aggregated value of the grey relational coefficient is calculated as follows:

$$
\rho_{j}(k)=\frac{1}{n} \sum_{k=1}^{n} \xi_{j}(k), \quad j=2,3, \ldots, N .
$$

The higher $\rho_{j}(k)$ is, the bigger impact the $j$ th variable has on the variable to be analyzed; on the contrary, the lower $\rho_{j}(k)$ is, the smaller impact the $j$ th element has on the variable to be analyzed. By this way, we can see how contribution of the input variables to output variable is changed over time.

Finally, the management of the company obtains the aggregated information vector $\operatorname{AIV}(j, k)=\left[\widehat{X}^{(0)}(j, k)\right.$, $\left.\operatorname{RPE}(j, k), \operatorname{ARPE}(j, k), \xi_{j}(k), \rho(j, k)\right]$ which sublimates the following important indicators:

(i) The forecasting model.

(ii) The relative percentage error of forecasting model.

(iii) The average relative percentage error of forecasting model. (iv) The grey relational coefficient between inputs and output for the $k$ th time point.

(v) The aggregated grey relational coefficient between inputs and output.

\section{Forecasting Model}

3.1. Concept of the Model. Overall operational efficiency measures have enjoyed a great deal of interest among planners analyzing the performance of an underground mine. Suppose the production of mine in period $k$ can be represented by mining technology set (MTS):

$$
\begin{aligned}
& \operatorname{MTS}(k)=\left\{\left(I(k), O(k): I(k) \in R_{+}^{g}, O(k)\right.\right. \\
& \left.\left.\quad \in R_{+}^{l}, I(k) \text { can realize } O(k)\right)\right\},
\end{aligned}
$$

where $I(k)=\left(i_{1}^{k}, i_{2}^{k}, \ldots, i_{g}^{k}\right)$ is the input mining technology vector and $O(k)=\left(o_{1}^{k}, o_{2}^{k}, \ldots, o_{l}^{k}\right)$ is the output vector which represents the indicators obtained from production. The MTS is the space of the feasible combinations of input-output vectors in period $k$.

The input vector of the MTS is composed of many variables but they can be divided into three main subspaces: characteristics of mineral deposit, underground mining methods, and mineral processing methods. The output vector is usually composed of the following variables: realized production rate and quality of produced mineral assets.

Operational efficiency is usually expressed by some kind of economic indicator. According to required type of operational efficiency, MTS can be transformed and joined to economic set (ES). This transformation means that some variables of $I(k)$ and $O(k)$ are used to calculate some variables of ES.

To express the operational efficiency of an existing underground mine we apply the concept of Degree of Operating Leverage (DOL). The DOL is the leverage ratio that sums up the effects of an amount of operating leverage on the company's earnings (revenues) before interests and taxes (EBIT).

The DOL during the period $k$ can be calculated with following formula (Weygandt et al.) [17]:

$$
\operatorname{DOL}(k)=\frac{\operatorname{REV}(k)-\mathrm{PC}(k)}{\operatorname{REV}(k)-\mathrm{PC}(k)-\mathrm{FC}(k)},
$$

where REV is revenues (USD), PC is production costs (USD), and FC is fixed costs (USD).

Operating leverage refers to the amount of operating fixed costs in the cost structure. DOL is the ratio of the relative change in sales. Implications are related to amplifying the changes in sales volume into larger changes in EBIT. Even in a perfectly competitive market, price plays a role in determining the DOL magnitude. Assume that a firm is currently operating with a positive profit. When market equilibrium price rises, the denominator in (17) rises reducing 
the DOL with no change in output, operating fixed cost, or unit variable cost. Consequently, breakeven output falls since the contribution margin is larger. DOL can vary due to changes in any of the variables appearing in (17). These variables include management determined choices (operating fixed cost and output levels); market determined parameters (price in a competitive market as time passes); and economic and engineering realities (unit variable costs, given operating fixed cost increases due to new capital acquisition) [18].

The higher value of DOL indicates that the business of mining company is exposed to the greater risk.

The input vector $X(k)=A(k) \cup B(k) \cup C(k)$ that is used to evaluate operational efficiency is represented as the union of three following sets:

$A(k)$ is a subset of the input mining technology variables.

$B(k)$ is a subset of the output mining technology variables.

$C(k)$ is a set of the external variables.

According to our problem, we create the vector space of input variables as follows:

$$
X(k)=\left[X_{j}(k)\right]=\left[x_{6, k}\right]=\left[\begin{array}{cccc}
x_{1,1} & x_{1,2} & \cdots & x_{1, k} \\
x_{2,1} & x_{2,2} & \cdots & x_{2, k} \\
x_{3,1} & x_{3,2} & \cdots & x_{3, k} \\
x_{4,1} & x_{4,2} & \cdots & x_{4, k} \\
x_{5,1} & x_{5,2} & \cdots & x_{5, k} \\
x_{6,1} & x_{6,2} & \cdots & x_{6, k}
\end{array}\right],
$$

where $x_{1, k}$ is ore production rate (t/year), $x_{2, k}$ is fixed costs (USD), $x_{3, k}$ is revenues (USD), $x_{4, k}$ is production costs (USD), $x_{5, k}$ is working days (days/year), and $x_{6, k}$ is degree of use of production capacity $(\%)$.

Let $y(1), y(2), \ldots, y(k)$ be a sequence of observed DOL values on an annual basis, that is, the major sequence factor. Equation (9) will be used for expressing the forecast model of DOL of an existing underground mine as follows:

$$
\frac{d y^{(1)}}{d k}+a y^{(1)}=b_{1} x_{1}^{(1)}+b_{2} x_{2}^{(1)}+\cdots+b_{N} x_{N}^{(1)} .
$$

The time sequence response formula of DOL is

$$
\begin{aligned}
\widehat{y}^{(1)}(k+1)= & \left\{y^{(0)}(1)-\sum_{j=1}^{6} \frac{b_{j}}{a} \cdot x_{j}^{(1)}(k+1)\right\} e^{-a k} \\
& +\sum_{j=1}^{6} \frac{b_{j}}{a} \cdot x_{j}^{(1)}(k+1), \\
& k=0,1,2, \ldots, n-1 .
\end{aligned}
$$

The fitting forecast value of $y_{k}^{(0)}$ can be obtained by the inverse AGO as follows:

$$
\begin{aligned}
& \widehat{y}^{(0)}(k)=\widehat{y}^{(1)}(k)-\widehat{y}^{(1)}(k-1), \quad k=2,3, \ldots, n, \\
& \widehat{y}^{(0)}(1)=y^{(0)}(1), \quad k=0 .
\end{aligned}
$$

For $k>n$ we can make forecasts of DOL as follows:

$$
\begin{aligned}
& \widehat{y}^{(1)}(n+h+1) \\
& =\left\{y^{(0)}(1)-\sum_{j=1}^{6} \frac{b_{j}}{a} \cdot x_{j}^{(1)}(n+h+1)\right\} e^{-a(n+h)} \\
& +\sum_{j=1}^{6} \frac{b_{j}}{a} \cdot x_{j}^{(1)}(n+h+1), \\
& \widehat{y}^{(0)}(n+h)=\widehat{y}^{(1)}(n+h)-\widehat{y}^{(1)}(n+h-1), \\
& h=1,2, \ldots, T-1,
\end{aligned}
$$

where $T$ is future time horizon.

The forecasting model should be able to involve a common time horizon, taking the characteristics of the input variables that directly affect the value of DOL. In this section, the proposed method of forecasting of DOL under multiple uncertainty and nonuniformity of input variables is outlined. The method is based mainly on simulating multiple realizations of the uncertain variables and making forecasts using value expectations.

According to the valuation function defined by (22), the expected value of DOL over future time is defined as follows:

$$
E\left(\widehat{y}^{(0)} \mid x_{1}, x_{2}, x_{3}, x_{4}, x_{5}, x_{6}, n+h\right) .
$$

Before we start to create forecasting process, it is necessary to divide the set of input variables into two subsets; $X(n+h)=$ $\operatorname{EXP}(n+h) \cup \operatorname{SIM}(n+h)$, where $\operatorname{EXP}(n+h)$ denotes the set composed of variables defined by experts, while $\operatorname{SIM}(n+h)$ denotes the set composed of variables defined by some kind of stochastic law. In our case these subsets are

$$
\begin{aligned}
& \operatorname{EXP}(n+h)=\left[x_{1}, x_{2}, x_{5}, x_{6}\right], \\
& \operatorname{SIM}(n+h)=\left[x_{3}, x_{4}\right] .
\end{aligned}
$$

Values of $x_{1}, x_{2}, x_{5}$, and $x_{6}$ are of deterministic nature while the others are stochastic.

\subsection{Volatility of the Input Variables}

3.2.1. Volatility of Revenues. Mining companies not having smelting facilities realize their revenues by selling their metal concentrates as a final product. Estimating revenues is, indeed, a difficult and risky activity. Annual mine revenue is calculated by multiplying the number of units produced and sold during the year by the sales price per unit. The annual mine revenue $\left(x_{3}\right)$ is calculated according to the following equation:

$$
\mathrm{REV}_{\text {year }}=Q_{\text {year }} \cdot \sum_{j=1}^{n} V_{j}^{\text {con }} \cdot \frac{G_{j} \cdot M_{j}}{m_{j}^{\text {con }}},
$$


where $Q_{\text {year }}$ is the annual production of ore $\left(x_{1}\right), V^{\text {con }}$ is the value of the metal concentrate, $G$ is the grade of ore mined (\%), $M$ is the mill recovery rate (\%), $m^{\text {con }}$ is the metal content of the concentrate (\%), and $n$ is the number of metal concentrates derived from the ore $(n>1$ for polymetallic deposits).

The first major component of the mine revenue calculation is annual production of concentrate. One of the key variables associated with annual concentrate production is the tonnage of ore mined. Annual ore tonnage is derived from the mining project schedule and is denoted $Q$.

The second key variable associated with determining the annual production of saleable units is the grade of the ore mined. The concept of the ore grade $(G)$ is defined as the ratio of useful mass of metal to the total mass of ore and its critical value fluctuates over space and can be estimated by normal probability density function. The use of normal distribution is based on geostatistical methods developed for evaluation of grades in mineral deposits. The deposit is sampled by means of drill-holes. Each sample gives us the information about mass of metal (grade) and we can create histogram of grades values. According to the obtained histogram adequate probability distribution function is selected. In most cases of mineral deposits normal distribution is used as representative function:

$$
G \sim N\left(\mu, \sigma^{2}\right) .
$$

At first sight, it seems that $G$ does not change its value over time, but if we take into consideration the mining front advances over time through different parts of deposit, then it is also time depending. For simplicity, we adopt the values of $G$ which belong to the same interval, defined by $\mu \pm 2 \sigma$, over future time horizon.

Most ores require beneficiation before saleable product can be produced. The resulting milling losses must be estimated and appropriate recovery percentages established. These recoveries are commonly estimated from a metallurgical testing program. Percentage recovery is the third basic variable which must be estimated to arrive at a final estimate of the annual production of saleable units extracted from the mine and is denoted $M$. A specific stochastic behavior that is used to quantify uncertainty related to mill recovery rate $(M)$ is uniform probability density function. Perhaps it is virtually certain that mill recovery will lie in interval $[a, b]$ but it is possible to achieve it by mineral processing control. For example, flotation is the most widely used method for the concentration of fine grained minerals. It takes advantage of the different physicochemical surface properties of minerals in particular their wettability, which can be a natural property or artificially changed by chemical reagents. By altering the hydrophobic (water repelling) or hydrophilic (water attracting) conditions of their surfaces, mineral particles suspended in water can be induced to adhere to air bubbles passing through a flotation cell or to remain in the pulp. The air bubbles pass to the upper surface of the pulp and form a froth, which, together with the attached hydrophobic minerals, can be removed. The tailings, containing the hydrophilic minerals, can be removed from the bottom of the cell. According to that, within interval $[a, b]$ no value is more likely than any other. This gives rise to a uniform distribution:

$$
M \sim \operatorname{unif}(a, b) .
$$

It seems that $M$ does not change its value over time, but if we take into consideration the fact that the flotation is influenced by many parameters and fact that it is very difficult to keep them constantly over time, then it is also time depending. For simplicity, we adopt the values of $M$ which belong to the same interval $[a, b]$ but $M$ takes the stochastic values for every year of the time horizon.

The second major component of the mine revenue calculation is unit sales price or unit metal concentrate sales price $\left(V^{\mathrm{con}}\right)$. It directly depends on mineral asset price, metal content of the concentrate, and metal recovery rate. Estimating future mineral prices is an exercise for which a high error of estimation invariably exists. The characteristically long preproduction periods of mining projects mean that their success will be determined by mineral prices five to ten years in the future.

The market risks related to mineral asset price $(P)$ are modeled with a special stochastic process, a mean reversion process. The mean reversion process has economic logic; for example, although the commodity prices have sensible shortterm oscillations, they tend to revert back to a "normal" longterm equilibrium level. The past values of the changes in this uncertain factor help predict the future. We will use a model where the metal spot price is assumed to follow the stochastic process [19]:

$$
d P=\alpha(\ln \bar{P}-\ln P) P d t+\sigma P d W .
$$

Let $x=\ln P$; applying Ito's lemma allows the characterization of the log price by an Ornstein-Uhlenbeck stochastic mean reverting process:

$$
d x=\alpha(\bar{x}-x) d t+\sigma d W
$$

with

$$
\bar{x}=\ln (\bar{P})-\frac{\sigma^{2}}{2 \alpha},
$$

where $\bar{P}$ is the long-run equilibrium metal price, $\alpha$ measures the speed of mean reversion to the long-run mean log price $\bar{P}, d W$ is an increment to a standard Brownian motion, and $\sigma$ refers to the price volatility rate. The metal price adjustment mechanism is accounted for by market forces. The correct discrete-time format for the continuous-time process of mean reversion is the stationary first-order autoregressive 


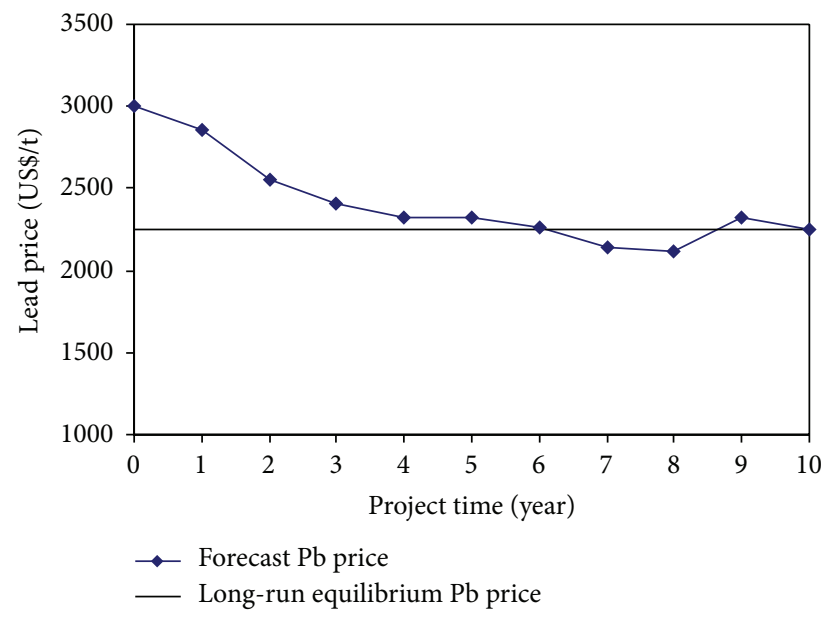

FIGURE 1: One simulated lead price path on a yearly time resolution.

process [20], so the sample path simulation equation for $x_{t}$ is performed by using exact discrete-time expression:

$$
\begin{aligned}
x_{t}= & x_{t-1} e^{-\alpha \Delta t}+\bar{x}\left(1-e^{-\alpha \Delta t}\right) \\
& +N(0,1) \sigma \sqrt{\frac{\left(1-e^{-2 \alpha \Delta t}\right)}{2 \alpha}},
\end{aligned}
$$

where $\Delta t$ is the fixed time interval from time $t$ to $t+1$ and $N(0,1)$ is the normally distributed random variable.

By substituting (31) to $P=e^{x}$, we have exact discrete-time equation for $P_{t}$, given by

$$
\begin{aligned}
& P_{t} \\
& =e^{\left\{\ln \left(P_{t-1}\right) e^{-\alpha \Delta t}+\left[\ln (\bar{P})-\sigma^{2} / 2 \alpha\right]\left(1-e^{-\alpha \Delta t}\right)+N(0,1) \sigma \sqrt{\left(1-e^{-2 \alpha \Delta t}\right) / 2 \alpha}\right\}} .
\end{aligned}
$$

In order to estimate the parameters of the mean reversion process, we run the following regression:

$$
d x_{t+1}=\beta_{0}+\beta_{1} x_{t}+\varepsilon
$$

where $\beta_{0}=\alpha \bar{x} d t$ and $\beta_{1}=-\alpha d t$. Hence, if we regress observation $d x$ against $x$, we can obtain estimates of $\beta_{0}$ and $\beta_{1} . \sigma$ is the standard deviation obtained from the regression. The speed of mean reversion $(\alpha)$ is the negative of the slope, while the long-run equilibrium $(\bar{P})$ is the intercept estimate of that regression divided by the speed of mean reversion.

Let $P=\left\{P_{t}, t=0,1, \ldots, T\right\}$ denote a price scenario with spot prices $P_{t}$, where $P_{t}$ is determined by (32). Figure 1 presents a sample path of the metal price (e.g., lead) simulated using the above equation.

In the purpose of $P$ simulation, we apply a metal price scenario for the time interval, $[n, n+T]$, with increment $\Delta t=1$.
The unit value of metal concentrate sales price can be expressed as follows:

$$
V^{\mathrm{con}}(t)=f\left(P(t), m^{\mathrm{con}}, m^{\mathrm{mr}}\right)
$$

where $m^{\mathrm{mr}}$ is the metal recovery rate (\%). The value of $V^{\text {con }}$ is calculated in different ways with respect to type of metal.

3.2.2. Volatility of Production Costs. Production costs (PC) are incurred directly in the production process. These costs include the ore and waste development of individual stopes, the actual stoping activities, the mine services providing logistical support to the miners, and the milling and processing of the ore at the plant. The uncertainties related to the future states of unit production costs are modeled with a special stochastic process, the geometric Brownian motion. Certain stochastic processes are functions of a Brownian motion process and these have many applications in finance, engineering, and the sciences. Some special processes are solutions of Itô-Doob type stochastic differential equations (Ladde, Sambandham) [21].

In this model, we apply a continuous time process using the Itô-Doob type stochastic differential equation to describe movement of unit production costs. A general stochastic differential equation takes the following form:

$$
\begin{aligned}
d \mathrm{CO}_{t} & =\rho \cdot\left(\mathrm{CO}_{t}, t\right) d t+\sigma \cdot\left(\mathrm{CO}_{t}, t\right) \cdot d W_{t}, \\
\mathrm{CO}_{t_{0}} & =\mathrm{CO}_{0} .
\end{aligned}
$$

Here, $t \geq t_{0}, W_{t}$ is a Brownian motion, and $\mathrm{CO}_{t}>0$; this is the cost process.

$\mathrm{CO}_{t}$ is called the geometric Brownian motion, which is solution of the following linear Itô-Doob type stochastic differential equation:

$$
d \mathrm{CO}_{t}=\rho \cdot \mathrm{CO}_{t} d t+\sigma \cdot \mathrm{CO}_{t} \cdot d W_{t}
$$

where $\rho$ is the drift, $\sigma$ is the volatility, and $W_{t}$ is normalized Brownian motion.

Using the Itô-Doob formula applied to $\left(\mathrm{CO}_{t}\right)=\ln \left(\mathrm{CO}_{t}\right)$, we can solve this equation:

$$
\mathrm{CO}_{t}=\mathrm{CO}_{t-1} \cdot e^{\left\{\left(\rho-\sigma^{2} / 2\right) \Delta t+N(0,1) \sigma \sqrt{\Delta t}\right\}} .
$$

Equation (37) describes an operating cost scenario with spot costs $\mathrm{CO}_{t}$.

Let $\mathrm{CO}=\left\{\mathrm{CO}_{t}, t=0,1, \ldots, T\right\}$ denote a cost scenario with spot costs $\mathrm{CO}_{t}$, where $\mathrm{CO}_{t}$ is determined by (37). Figure 2 presents a sample paths $(s=1,2, \ldots, S)$ of the unit production cost simulated using (37) $S$ times.

In the purpose of CO simulation, we apply a cost scenario for the time interval, $[n, n+T]$, with increment $\Delta t=1$. 


$$
\operatorname{DOL}_{T}^{s=1}=\left[\begin{array}{cccc}
s=1 & s=1 & \ldots & s=1 \\
x_{1,1} & x_{1,2} & \ldots & x_{1, T} \\
x_{2,1} & x_{2,2} & \ldots & x_{2, T} \\
x_{3,1} & x_{3,2} & \ldots & x_{3, T} \\
x_{4,1} & x_{4,2} & \ldots & x_{4, T} \\
x_{5,1} & x_{5,2} & \ldots & x_{5, T} \\
x_{6,1} & x_{6,2} & \ldots & x_{6, T} \\
\downarrow & \downarrow & \downarrow & \downarrow \\
\text { equation }(22) & \text { equation } & \text { equation } & \text { equation }(22) \\
\downarrow & \downarrow & \downarrow & \downarrow \\
\hat{y}_{1}^{(1) s=1} & \widehat{y}_{2}^{(1) s=1} & \ldots & \widehat{y}_{T}^{(1) s=1} \\
\downarrow & \downarrow & \downarrow & \downarrow \\
\hat{y}_{1}^{(0) s=1} & \hat{y}_{2}^{(0) s=1} & \ldots & \widehat{y}_{T}^{(0) s=1}
\end{array}\right] .
$$

Once the simulations $\mathrm{DOL}_{T}^{s}, s=1,2, \ldots, S$, have been obtained, they can be used to estimate the distribution of the DOL for every year of the defined time horizon. The expected values of the DOL can be expressed by the following vector space:

$$
E\left(\mathrm{DOL}_{T}^{S}\right)=\left[\begin{array}{cccc}
\widehat{y}_{1}^{(0) s=1} & \widehat{y}_{2}^{(0) s=1} & \cdots & \widehat{y}_{T}^{(0) s=1} \\
\widehat{y}_{1}^{(0) s=2} & \widehat{y}_{2}^{(0) s=2} & \cdots & \widehat{y}_{T}^{(0) s=2} \\
\vdots & \vdots & \ddots & \vdots \\
\widehat{y}_{1}^{(0) s=S} & \widehat{y}_{2}^{(0) s=S} & \cdots & \widehat{y}_{T}^{(0) s=S} \\
\downarrow & \downarrow & \downarrow & \downarrow \\
E\left(\hat{y}_{1}^{(0)}\right) & E\left(\hat{y}_{2}^{(0)}\right) & \cdots & E\left(\widehat{y}_{T}^{(0)}\right)
\end{array}\right] .
$$

According to (41), the management of the company obtains the forecasting information vector of DOL:

$$
\begin{aligned}
\operatorname{FIV} & (j, T)=E(\mathrm{DOL}) \\
& =\left[\begin{array}{llll}
E\left(\mathrm{DOL}_{1}\right) & E\left(\mathrm{DOL}_{2}\right) & \cdots & E\left(\mathrm{DOL}_{T}\right)
\end{array}\right]
\end{aligned}
$$

This vector concerns the information of the possible future states of the Degree of Operating Leverage over defined time horizon.

Space of simulation for $s=1$ and $k>n$, where the first seven rows concern the evolution paths of the DOL and input variables while the rest concern evolution paths of the grey relational coefficient, can be represented as follows:

$$
\xi_{j, T}^{s=1}=\left[\begin{array}{cccc}
s=1 & s=1 & \ldots & s=1 \\
\widehat{y}_{1}^{(0)} & \widehat{y}_{2}^{(0)} & \ldots & \widehat{y}_{T}^{(0)} \\
x_{1,1} & x_{1,2} & \ldots & x_{1, T} \\
x_{2,1} & x_{2,2} & \ldots & x_{2, T} \\
x_{3,1} & x_{3,2} & \ldots & x_{3, T} \\
x_{4,1} & x_{4,2} & \ldots & x_{4, T} \\
x_{5,1} & x_{5,2} & \ldots & x_{5, T} \\
x_{6,1} & x_{6,2} & \ldots & x_{6, T} \\
\downarrow & \downarrow & \downarrow & \downarrow \\
\text { equation }(14) & \text { equation } & \text { equation } & \text { equation }(14) \\
\downarrow & \downarrow & \downarrow & \downarrow \\
\xi_{1,1}^{s=1} & \xi_{1,2}^{s=1} & \ldots & \xi_{1, T}^{s=1} \\
\vdots & \vdots & \ddots & \vdots \\
\xi_{6,1}^{s=1} & \xi_{6,2}^{s=1} & \ldots & \xi_{6, T}^{s=1}
\end{array}\right] .
$$


Once the simulations $\xi_{j, T}^{s}, s=1,2, \ldots, S$, have been obtained, they can be used to estimate the distribution of the $\xi_{j}$ for every year of the defined time horizon. The expected values of the $\xi_{j}$ can be expressed by the following vector space:

$$
E\left(\xi_{j, T}^{S}\right)=\left[\begin{array}{llll}
E\left(\xi_{1,1}^{S}\right) & E\left(\xi_{1,2}^{S}\right) & \cdots & E\left(\xi_{1, T}^{S}\right) \\
E\left(\xi_{2,1}^{S}\right) & E\left(\xi_{2,2}^{S}\right) & \cdots & E\left(\xi_{2, T}^{S}\right) \\
E\left(\xi_{3,1}^{S}\right) & E\left(\xi_{3,2}^{S}\right) & \cdots & E\left(\xi_{3, T}^{S}\right) \\
E\left(\xi_{4,1}^{S}\right) & E\left(\xi_{4,2}^{S}\right) & \cdots & E\left(\xi_{4, T}^{S}\right) \\
E\left(\xi_{5,1}^{S}\right) & E\left(\xi_{5,2}^{S}\right) & \cdots & E\left(\xi_{5, T}^{S}\right) \\
E\left(\xi_{6,1}^{S}\right) & E\left(\xi_{6,2}^{S}\right) & \cdots & E\left(\xi_{6, T}^{S}\right)
\end{array}\right] .
$$

The expected values of the aggregated grey relational coefficient are calculated as follows:

$$
\rho_{j}=\frac{1}{h} \sum_{h=1}^{T}\left\{E\left(\xi_{j, h}^{S}\right)\right\}, \quad j=1,2, \ldots, 6
$$

According to (45), the management of the company obtains the forecasting information vector of the aggregated grey relational coefficient:

$$
\rho(j)=\left[\begin{array}{c}
\rho(1) \\
\rho(2) \\
\vdots \\
\rho(6)
\end{array}\right] .
$$

\section{Application of the Procedure}

4.1. A Numerical Example Statement. A management of an operating underground zinc mine is trying to forecast the future states of operational efficiency for five years ahead. For this problem, the input parameters that are required for the forecasting are given in Tables 2 and 3. In order to define values of production rate, fixed costs, working days, and degree of use of production capacity, three experts are included into process of estimation. Note that the situation is hypothetical and numbers used are to permit calculation.
Values of the input parameters are similar to the real environment of mining.

\subsection{A Numerical Example Solution}

Step 1 (forecasting model). Transformations of the original data sequences by $\mathrm{AGO}$ are as follows:

$$
\begin{aligned}
& Y^{(0)}=\left[\begin{array}{llllll}
1.219 & 1.421 & 1.333 & 1.676 & 1.437
\end{array}\right] \\
& Y^{(1)}=\left[\begin{array}{llllll}
1.219 & 2.640 & 3.973 & 5.649 & 7.086
\end{array}\right] \\
& X_{1}^{(0)}=\left[\begin{array}{llllll}
100000 & 95000 & 100000 & 100000 & 100000
\end{array}\right] \\
& X_{1}^{(1)}=\left[\begin{array}{llllll}
100000 & 195000 & 295000 & 395000 & 495000
\end{array}\right] \\
& X_{2}^{(0)}=\left[\begin{array}{llllll}
1200000 & 1500000 & 1100000 & 1400000 & 1600000
\end{array}\right], \\
& X_{2}^{(1)}=\left[\begin{array}{llllll}
1200000 & 2700000 & 3800000 & 5200000 & 6800000
\end{array}\right], \\
& X_{3}^{(0)} \\
& =\left[\begin{array}{lllll}
11065884 & 10773877 & 10137834 & 9145279 & 10823137
\end{array}\right], \\
& X_{3}^{(1)} \\
& =\left[\begin{array}{lllll}
11065884 & 21839761 & 31977595 & 41122874 & 51946011
\end{array}\right], \\
& X_{4}^{(0)}=\left[\begin{array}{lllll}
4387000 & 5714000 & 5740000 & 5676000 & 5564000
\end{array}\right], \\
& X_{4}^{(1)} \\
& =\left[\begin{array}{lllll}
4387000 & 10101000 & 15841000 & 21517000 & 27081000
\end{array}\right], \\
& X_{5}^{(0)}=\left[\begin{array}{lllll}
330 & 310 & 340 & 300 & 320
\end{array}\right], \\
& X_{5}^{(1)}=\left[\begin{array}{lllll}
330 & 640 & 980 & 1280 & 1600
\end{array}\right], \\
& X_{6}^{(0)}=\left[\begin{array}{lllll}
90 & 85 & 93 & 82 & 88
\end{array}\right], \\
& X_{6}^{(1)}=\left[\begin{array}{lllll}
90 & 175 & 268 & 350 & 438
\end{array}\right]
\end{aligned}
$$

Calculation of the average generation of adjacent sample sequence of $Y^{(1)}(k)$ is as follows:

$$
\begin{aligned}
Y^{(1)} & =\left[\begin{array}{lllll}
1.219 & 2.640 & 3.973 & 5.649 & 7.086
\end{array}\right], \\
Z^{(1)}\left(Y^{(1)}\right) & =\left[\begin{array}{lllll}
1.929 & 3.307 & 4.812 & 6.369
\end{array}\right] .
\end{aligned}
$$

Construction of the matrix $B$ and matrix $Y$ is as follows:

$$
\begin{aligned}
& B=\left[\begin{array}{llllllll}
-1.219 & 195000 & 2700000 & 21839761 & 10101000 & 640 & 175 \\
-3.307 & 295000 & 3800000 & 31977595 & 15841000 & 980 & 268 \\
-4.812 & 395000 & 5200000 & 41122874 & 21517000 & 1280 & 350 \\
-6.369 & 495000 & 6800000 & 51946011 & 27081000 & 1600 & 438
\end{array}\right] \\
& Y=\left[\begin{array}{l}
1.421 \\
1.333 \\
1.676 \\
1.437
\end{array}\right]
\end{aligned}
$$


TABLE 2: Input parameters of observed period.

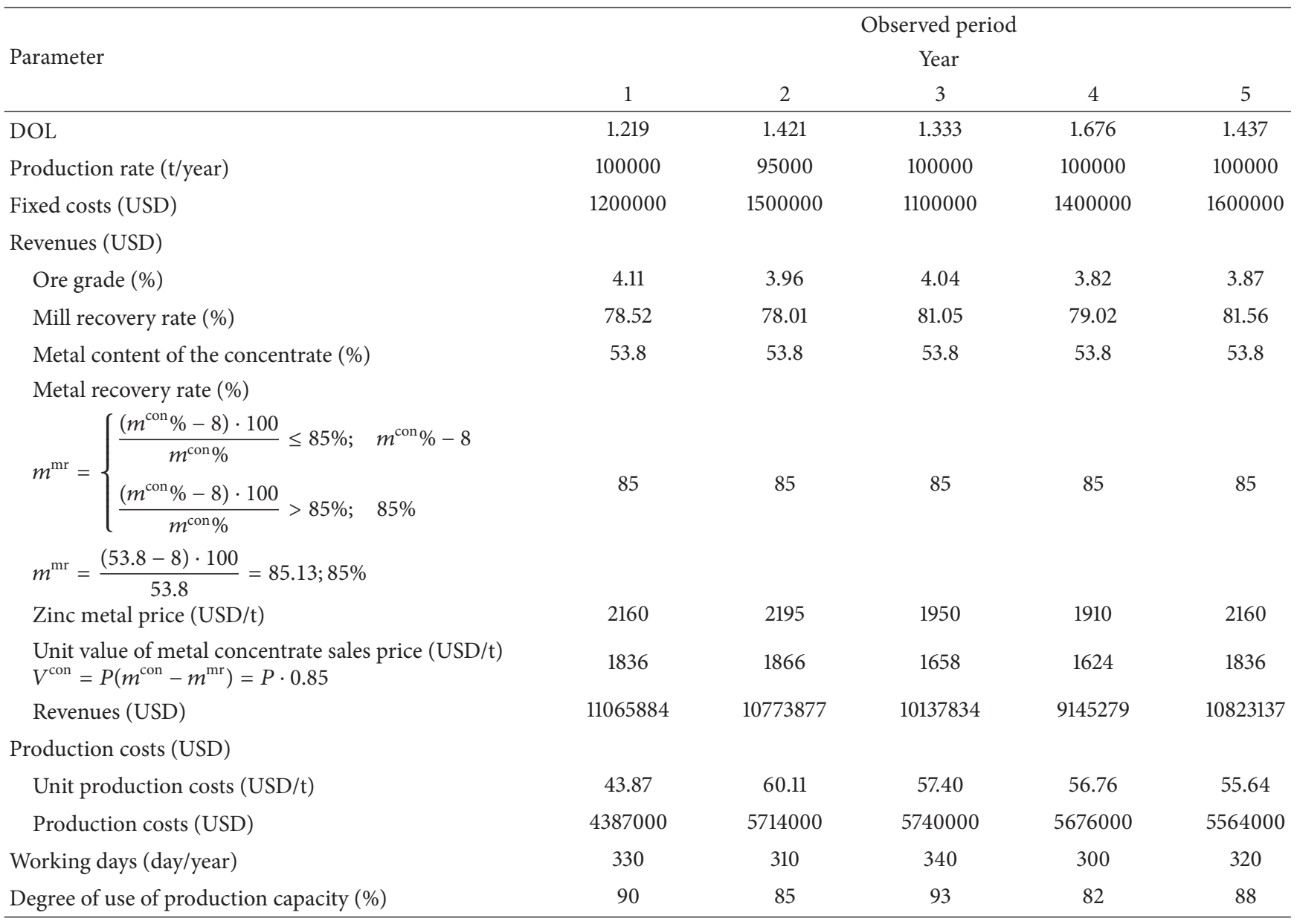

TABLE 3: Input parameters required for simulation of DOL.

\begin{tabular}{|c|c|c|c|c|c|}
\hline \multirow{3}{*}{ Parameter } & \multicolumn{5}{|c|}{ Value } \\
\hline & \multicolumn{5}{|c|}{ Year } \\
\hline & 6 & 7 & 8 & 9 & 10 \\
\hline Production rate (t/year) & 100000 & 105000 & 97000 & 100000 & 110000 \\
\hline Fixed costs (USD) & 1600000 & 1800000 & 1500000 & 1700000 & 2000000 \\
\hline \multicolumn{6}{|l|}{ Revenues (USD) } \\
\hline Ore grade $(\%)$-normal distribution & \multicolumn{5}{|c|}{ Min. 3.45; medium 4.06; max. 4.68; volatility 0.205} \\
\hline Mill recovery rate (\%)-uniform distribution & \multicolumn{5}{|c|}{ Min. 77; medium 78.5; max. 80; volatility 0.866} \\
\hline Metal content of the concentrate (\%) & \multicolumn{5}{|c|}{53.8} \\
\hline Metal recovery rate $(\%)$ & \multicolumn{5}{|c|}{85} \\
\hline Zinc metal price (USD/t)-mean reversion process & \multicolumn{5}{|c|}{$\begin{array}{l}\text { Spot value 2113; equilibrium metal price } 2277 \text {; speed of } \\
\text { mean reversion } 0.9221 \text {; price volatility rate } 0.2734\end{array}$} \\
\hline \multicolumn{6}{|l|}{ Production costs (USD) } \\
\hline Unit production costs (USD/t)-geometric Brownian motion & \multicolumn{5}{|c|}{ Spot value 65 ; drift 0.02382 ; cost volatility 0.09351} \\
\hline Working days (day/year) & 330 & 330 & 340 & 340 & 340 \\
\hline Degree of use of production capacity (\%) & 86 & 90 & 92 & 85 & 93 \\
\hline Number of simulations & \multicolumn{5}{|c|}{500} \\
\hline
\end{tabular}


TABLE 4: Fitted values of DOL.

\begin{tabular}{|c|c|c|c|c|c|}
\hline \multirow{2}{*}{ Error } & \multicolumn{5}{|c|}{ Year } \\
\hline & 1 & 2 & 3 & 4 & 5 \\
\hline DOL-AGO values & & 2.292 & 3.642 & 5.291 & 6.546 \\
\hline DOL-inverse AGO values & 1.219 & 1.073 & 1.350 & 1.649 & 1.255 \\
\hline
\end{tabular}

TABLE 5: Error estimation of the model.

\begin{tabular}{|c|c|c|c|c|c|}
\hline \multirow{2}{*}{ Error } & \multicolumn{5}{|c|}{ Year } \\
\hline & 1 & 2 & 3 & 4 & 5 \\
\hline DOL-observed values & 1.219 & 1.421 & 1.333 & 1.676 & 1.437 \\
\hline DOL-fitted values & 1.219 & 1.073 & 1.350 & 1.649 & 1.255 \\
\hline RPE (\%) & 0 & 24.47 & 1.28 & 1.63 & 12.70 \\
\hline ARPE (\%) & & & 10.02 & & \\
\hline
\end{tabular}

The constructed AGO sequence of our problem is represented by the following matrix form:

$$
\left[\begin{array}{l}
1.421 \\
1.333 \\
1.676 \\
1.437
\end{array}\right]=\left[\begin{array}{llllllll}
-1.219 & 195000 & 2700000 & 21839761 & 10101000 & 640 & 175 \\
-3.307 & 295000 & 3800000 & 31977595 & 15841000 & 980 & 268 \\
-4.812 & 395000 & 5200000 & 41122874 & 21517000 & 1280 & 350 \\
-6.369 & 495000 & 6800000 & 51946011 & 27081000 & 1600 & 438
\end{array}\right]\left[\begin{array}{c}
a \\
b_{2} \\
\vdots \\
b_{\mathrm{N}}
\end{array}\right]
$$

According to $\widehat{a}=\left(B^{T} B\right)^{-1} B^{T} Y$ we obtain the following factors of the matrix $\widehat{a}=\left[1.5379 ; 0.0001129 ;-1.03377 \cdot 10^{-6} ; 1.304\right.$. $\left.10^{-7} ;-1.4598 \cdot 10^{-7} ;-0.0042024 ;-0.0796303\right]^{T}$. Values of the determined coefficients are $a=1.5379 ; b_{1}=0.0001129 ; b_{2}=$ $-1.03377 \cdot 10^{-6} ; b_{3}=1.304 \cdot 10^{-7} ; b_{4}=-1.4598 \cdot 10^{-7} ; b_{5}=$ $-0.0042024 ; b_{6}=-0.0796303$.

The AGO time sequence response formula of DOL is

$$
\begin{aligned}
& \widehat{y}^{(1)}(k+1)=\left\{1.219-7.3462 \cdot 10^{-5} x_{1}^{(1)}(k+1)\right. \\
& +6.748 \cdot 10^{-7} x_{2}^{(1)}(k+1)-8.479 \cdot 10^{-8} x_{3}^{(1)}(k+1) \\
& +9.492 \cdot 10^{-8} x_{4}^{(1)}(k+1)+0.0027325 x_{5}^{(1)}(k+1) \\
& \left.+0.0517784 x_{6}^{(1)}(k+1)\right\} e^{-1.5379 k} \\
& +7.3462 \cdot 10^{-5} x_{1}^{(1)}(k+1)-6.748 \cdot 10^{-7} x_{2}^{(1)}(k \\
& +1)+8.479 \cdot 10^{-8} x_{3}^{(1)}(k+1)-9.492 \cdot 10^{-8} x_{4}^{(1)}(k \\
& +1)-0.0027325 x_{5}^{(1)}(k+1)-0.0517784 x_{6}^{(1)}(k \\
& +1) ; \quad k=0,1,2,3,4 .
\end{aligned}
$$

AGO and inverse AGO values of the time sequence response formula of DOL are represented by Table 4 .
The adequacy of the obtained time sequence response formula is obtained by using (12) and summarized in Table 5.

Step 2 (grey relevance analysis). Applying (13) we obtain the following results of equalization (see Tables 6 and 7).

Absolute values of $\Delta_{j}(k)=\left|\mathrm{DOL}^{\prime}(k)-x_{j}^{\prime}(k)\right|$ are represented by Table 8 .

Extreme values of $\Delta_{j}(k)$ are represented by Table 9 .

Grey relational (relevance) analysis of $\operatorname{GM}(1,6)$ is represented by Table 10 .

According to Table 10, we obtain the rank order of relevancy of the influencing variables over observed time as follows:

$$
\begin{aligned}
& \text { Year 1: } X_{4}>X_{2}>X_{1}>X_{6}>X_{5}>X_{3} . \\
& \text { Year 2: }\left(X_{1}=X_{5}=X_{6}\right)>X_{3}>X_{4}>X_{2} . \\
& \text { Year 3: } X_{2}>X_{3}>X_{1}>X_{6}>X_{5}>X_{4} . \\
& \text { Year 4: } X_{3}>X_{6}>X_{5}>X_{1}>X_{2}>X_{4} . \\
& \text { Year 5: } X_{5}>X_{6}>X_{1}>X_{3}>X_{4}>X_{2} .
\end{aligned}
$$

According to aggregated values, we obtain the final rank order of relevancy of the influencing variables as follows: $X_{3}>$ $X_{6}>X_{5}>X_{1}>X_{4}>X_{2}$.

Step 3 (simulation of the influencing sequence variables and DOL). Scenario of zinc price is represented by Table 11. 
TABLE 6: Sum of the major and influencing sequence variables.

\begin{tabular}{|c|c|c|c|c|c|}
\hline $\operatorname{DOL}(k)$ & 1.219 & 1.421 & 1.334 & 1.677 & 1.437 \\
\hline$X_{1}(k)$ & 100000 & 95000 & 100000 & 100000 & 100000 \\
\hline$X_{2}(k)$ & 1200000 & 1500000 & 1100000 & 1400000 & 1600000 \\
\hline$X_{3}(k)$ & 11065884 & 10773876 & 10137834 & 9145278 & 10823136 \\
\hline$X_{4}(k)$ & 4387000 & 5714000 & 5740000 & 5676000 & 5564000 \\
\hline$X_{5}(k)$ & 330 & 310 & 340 & 300 & 320 \\
\hline$X_{6}(k)$ & 90 & 85 & 93 & 82 & 88 \\
\hline Sum & 16753305 & 18083273 & 17078268 & 16321662 & 18087545 \\
\hline
\end{tabular}

TABLE 7: Equalized values of the major and influencing sequence variables.

\begin{tabular}{lccccc}
\hline $\mathrm{DOL}^{\prime}(k)$ & $7.28 E-08$ & $7.86 E-08$ & $7.81 E-08$ & $1.03 E-07$ & $7.95 E-08$ \\
\hline$X_{1}^{\prime}(k)$ & 0.005969 & 0.005253 & 0.005855 & 0.006127 & 0.005529 \\
\hline$X_{2}^{\prime}(k)$ & 0.071628 & 0.08295 & 0.064409 & 0.085776 & 0.088459 \\
\hline$X_{3}^{\prime}(k)$ & 0.660519 & 0.595792 & 0.59361 & 0.560315 & 0.598375 \\
\hline$X_{4}^{\prime}(k)$ & 0.261859 & 0.315983 & 0.3361 & 0.347759 & 0.307615 \\
\hline$X_{5}^{\prime}(k)$ & $1.97 E-05$ & $1.71 E-05$ & $1.99 E-05$ & $1.84 E-05$ & $4.77 E-05$ \\
\hline$X_{6}^{\prime}(k)$ & $5.37 E-06$ & $4.7 E-06$ & $5.45 E-06$ & $5.02 E-06$ & 4.06 \\
\hline
\end{tabular}

TABLE 8: Absolute values of $\Delta_{j}(k)$.

\begin{tabular}{lccccc}
\hline$\Delta_{1}(k)$ & 0.005969 & 0.005253 & 0.005855 & 0.006127 & 0.005529 \\
\hline$\Delta_{2}(k)$ & 0.071628 & 0.08295 & 0.064409 & 0.085775 & 0.088459 \\
\hline$\Delta_{3}(k)$ & 0.660519 & 0.595792 & 0.59361 & 0.560315 & 0.598375 \\
\hline$\Delta_{4}(k)$ & 0.261859 & 0.315983 & 0.3361 & 0.347759 & 0.307615 \\
\hline$\Delta_{5}(k)$ & $1.96 E-05$ & $1.71 E-05$ & $1.98 E-05$ & $1.83 E-05$ & $1.76 E-05$ \\
\hline$\Delta_{6}(k)$ & $5.30 E-06$ & $4.62 E-06$ & $5.37 E-06$ & $4.92 E-06$ & $4.79 E-06$ \\
\hline
\end{tabular}

TABle 9: Min. and max. of $\Delta_{j}(k)$.

\begin{tabular}{lcc}
\hline & Min. & Max. \\
\hline$\Delta_{1}(k)$ & 0.005253 & 0.006127 \\
$\Delta_{2}(k)$ & 0.064409 & 0.088459 \\
$\Delta_{3}(k)$ & 0.560315 & 0.660519 \\
$\Delta_{4}(k)$ & 0.261859 & 0.347759 \\
$\Delta_{5}(k)$ & $1.71 E-05$ & $1.98 E-05$ \\
$\Delta_{6}(k)$ & $4.62 E-06$ & $5.37 E-06$ \\
\hline
\end{tabular}

TABLE 10: Correlation matrix.

\begin{tabular}{lcccccc}
\hline $\begin{array}{l}\text { DOL }(k) / X_{j} \\
\theta=0.5\end{array}$ & DOL(1) & DOL $(2)$ & DOL $(3)$ & DOL(4) & DOL(5) & Aggregated value \\
\hline$X_{1}$ & 0.92078 & 1 & 0.93251 & 0.90497 & 0.96797 & 0.94524 \\
\hline$X_{2}$ & 0.93769 & 0.85421 & 1 & 0.83565 & 0.81875 & 0.88926 \\
\hline$X_{3}$ & 0.89886 & 0.96169 & 0.96396 & 1 & 0.95901 & 0.95670 \\
\hline$X_{4}$ & 1 & 0.88951 & 0.85442 & 0.83532 & 0.90497 & 0.89684 \\
\hline$X_{5}$ & 0.91331 & 1 & 0.90701 & 0.95695 & 0.98009 & 0.95147 \\
\hline
\end{tabular}


TABLE 11: Mean reversion process of zinc price.

\begin{tabular}{lc}
\hline Year 6 & $P_{6}=e^{\left\{\ln (2113) \cdot e^{-0.9221}+\left[\ln (2277)-0.2734^{2} /(2 \cdot 0.9221)\right]\left(1-e^{-0.9221}\right)+N(0,1) \cdot 0.2734 \cdot \sqrt{\left.\left(1-e^{-2 \cdot 0.9221}\right) / 2 \cdot 0.9221\right\}}\right.}$ \\
\hline Year 7 & $P_{7}=e^{\left\{\ln \left(P_{6}\right) \cdot e^{-0.9221}+\left[\ln (2277)-0.2734^{2} /(2 \cdot 0.9221)\right]\left(1-e^{-0.9221}\right)+N(0,1) \cdot 0.2734 \cdot \sqrt{\left.\left(1-e^{-2 \cdot 0.9221}\right) / 2 \cdot 0.9221\right\}}\right.}$ \\
\hline Year 8 & $P_{8}=e^{\left\{\ln \left(P_{7}\right) \cdot e^{-0.9221}+\left[\ln (2277)-0.2734^{2} /(2 \cdot 0.9221)\right]\left(1-e^{-0.9221}\right)+N(0,1) \cdot 0.2734 \cdot \sqrt{\left.\left(1-e^{-2 \cdot 0.9221}\right) / 2 \cdot 0.9221\right\}}\right.}$ \\
\hline Year 9 & $P_{9}=e^{\left\{\ln \left(P_{8}\right) \cdot e^{-0.9221}+\left[\ln (2277)-0.2734^{2} /(2 \cdot 0.9221)\right]\left(1-e^{-0.9221}\right)+N(0,1) \cdot 0.2734 \cdot \sqrt{\left.\left(1-e^{-2 \cdot 0.9221}\right) / 2 \cdot 0.9221\right\}}\right.}$ \\
\hline Year 10 & $P_{10}=e^{\left\{\ln \left(P_{9}\right) \cdot e^{-0.9221}+\left[\ln (2277)-0.2734^{2} /(2 \cdot 0.9221)\right]\left(1-e^{-0.9221}\right)+N(0,1) \cdot 0.2734 \cdot \sqrt{\left.\left(1-e^{-2 \cdot 0.9221}\right) / 2 \cdot 0.9221\right\}}\right.}$ \\
\hline
\end{tabular}

TABLE 12: Geometric Brownian motion of unit production costs.

\begin{tabular}{ll}
\hline Year 6 & $\mathrm{CO}_{6}=65 \cdot e^{\left\{\left(0.02382-0.09351^{2} / 2\right)+N(0,1) \cdot 0.09351\right\}}$ \\
\hline Year 7 & $\mathrm{CO}_{7}=\mathrm{CO}_{6} \cdot e^{\left\{\left(0.02382-0.09351^{2} / 2\right)+N(0,1) \cdot 0.09351\right\}}$ \\
\hline Year 8 & $\mathrm{CO}_{8}=\mathrm{CO}_{7} \cdot e^{\left\{\left(0.02382-0.09351^{2} / 2\right)+N(0,1) \cdot 0.09351\right\}}$ \\
\hline Year 9 & $\mathrm{CO}_{9}=\mathrm{CO}_{8} \cdot e^{\left\{\left(0.02382-0.09351^{2} / 2\right)+N(0,1) \cdot 0.09351\right\}}$ \\
\hline Year 10 & $\mathrm{CO}_{10}=\mathrm{CO}_{9} \cdot e^{\left\{\left(0.02382-0.09351^{2} / 2\right)+N(0,1) \cdot 0.09351\right\}}$ \\
\hline
\end{tabular}

TABLE 13: One simulation path of DOL.

\begin{tabular}{|c|c|c|c|c|c|}
\hline \multirow{3}{*}{ Parameter } & \multicolumn{5}{|c|}{ Value } \\
\hline & \multicolumn{5}{|c|}{ Year } \\
\hline & 6 & 7 & 8 & 9 & 10 \\
\hline Production rate ( $\mathrm{t} /$ year) & 100000 & 105000 & 97000 & 100000 & 110000 \\
\hline Fixed costs (USD) & 1600000 & 1800000 & 1500000 & 1700000 & 2000000 \\
\hline \multicolumn{6}{|l|}{ Revenues (USD) } \\
\hline Ore grade (\%)-normal distribution & 4.07 & 3.78 & 4.31 & 4.01 & 3.86 \\
\hline Mill recovery rate (\%)-uniform distribution & 79.27 & 78.54 & 78.62 & 77.71 & 78.32 \\
\hline Metal content of the concentrate (\%) & 53.8 & 53.8 & 53.8 & 53.8 & 53.8 \\
\hline Metal recovery rate $(\%)$ & 85 & 85 & 85 & 85 & 85 \\
\hline Zinc metal price (USD/t)-mean reversion process & 2025 & 1936 & 2064 & 2409 & 2120 \\
\hline Revenues (USD) & 13040642 & 12152559 & 13638024 & 15254913 & 14228955 \\
\hline \multicolumn{6}{|l|}{ Production costs (USD) } \\
\hline Unit production costs (USD/t)-geometric Brownian motion & 71.56 & 88.33 & 90.77 & 98.01 & 95.87 \\
\hline Production costs (USD) & 7156388 & 9274793 & 8805646 & 9801869 & 10546252 \\
\hline Working days (day/year) & 330 & 330 & 340 & 340 & 340 \\
\hline Degree of use of production capacity (\%) & 86 & 90 & 92 & 85 & 93 \\
\hline \multicolumn{6}{|c|}{$\begin{array}{c}\widehat{y}^{(1)}(k+1)=\left\{1.219-7.3462 \cdot 10^{-5} x_{1}^{(1)}(k+1)+6.748 \cdot 10^{-7} x_{2}^{(1)}(k+1)-8.479 \cdot 10^{-8} x_{3}^{(1)}(k+1)+9.492 \cdot 10^{-8} x_{4}^{(1)}(k+1)\right. \\
\left.+0.0027325 x_{5}^{(1)}(k+1)+0.0517784 x_{6}^{(1)}(k+1)\right\} e^{-1.5379 k}+7.3462 \cdot 10^{-5} x_{1}^{(1)}(k+1)-6.748 \cdot 10^{-7} x_{2}^{(1)}(k+1) \\
+8.479 \cdot 10^{-8} x_{3}^{(1)}(k+1)-9.492 \cdot 10^{-8} x_{4}^{(1)}(k+1)-0.0027325 x_{5}^{(1)}(k+1)-0.0517784 x_{6}^{(1)}(k+1) \\
k=5+h ; h=0,1,2,3,4\end{array}$} \\
\hline DOL-AGO & 7.892 & 8.981 & 9.723 & 10.955 & 12.147 \\
\hline DOL-inverse AGO & 1.346 & 1.089 & 0.742 & 1.232 & 1.192 \\
\hline
\end{tabular}

Scenario of unit production costs is represented by Table 12.

Results of forecasting of DOL generated by the GM $(1,6)$ (see (51)) for a single simulation are represented by Table 13.

This act is repeated five hundred times and set of five hundred possible states of nature is obtained for every year of the time horizon. The expected DOL values, $E(\mathrm{DOL}(6)), E(\mathrm{DOL}(7)), \ldots, E(\mathrm{DOL}(10)), \quad$ are calculated from the simulation results, that is, from the sets of possible states of nature. The forecasting of the DOL is represented by Figure 3 and summary Table 14.

Probability and cumulative density function of forecasted DOL for 6 th year are represented by Figure 4 .

Step 4 (grey relevance analysis of results obtained by simulation). Applying (13) we obtain the following results of equalization (see Tables 15 and 16). 
TABLE 14: Summary statistics.

\begin{tabular}{|c|c|c|c|c|c|}
\hline \multirow{3}{*}{ Statistic parameter } & \multicolumn{5}{|c|}{ Value } \\
\hline & \multicolumn{5}{|c|}{ Year } \\
\hline & 6 & 7 & 8 & 9 & 10 \\
\hline Sample & 500 & 500 & 500 & 500 & 500 \\
\hline Mean (expected) value of DOL & 1.491 & 1.525 & 0.951 & 1.403 & 1.574 \\
\hline Median & 1.469 & 1.494 & 0.945 & 1.397 & 1.571 \\
\hline Standard deviation & 0.2512 & 0.2745 & 0.2631 & 0.2740 & 0.3163 \\
\hline Max. & 2.470 & 2.543 & 1.766 & 2.471 & 2.940 \\
\hline Min. & 0.9073 & 0.8394 & 0.2065 & 0.5978 & 0.5828 \\
\hline Range & 1.562 & 1.703 & 1.559 & 1.872 & 2.357 \\
\hline Q (75\%) & 1.646 & 1.698 & 1.105 & 1.573 & 1.752 \\
\hline Q (25\%) & 1.293 & 1.340 & 0.761 & 1.227 & 1.379 \\
\hline $\mathrm{Q}(75 \%)-\mathrm{Q}(25 \%)$ & 0.352 & 0.358 & 0.344 & 0.346 & 0.373 \\
\hline Asymmetry (Skewness) & 0.6235 & 0.5085 & 0.4129 & 0.3726 & 0.2453 \\
\hline Kurtosis & 0.3917 & 0.3205 & 0.2378 & 0.7502 & 1.1323 \\
\hline Standard error & 0.01123 & 0.01227 & 0.01176 & 0.01225 & 0.01414 \\
\hline Reliability coefficient $(1-\alpha)$ & 0.95 & 0.95 & 0.95 & 0.95 & 0.95 \\
\hline Reliability factor & 1.96 & 1.96 & 1.96 & 1.96 & 1.96 \\
\hline Reliability interval-upper limit & 1.513 & 1.549 & 0.973 & 1.427 & 1.601 \\
\hline Reliability interval-lower limit & 1.469 & 1.501 & 0.927 & 1.378 & 1.545 \\
\hline Mean (expected) value (\%) & 52.90 & 53.80 & 51.40 & 50.20 & 50.70 \\
\hline
\end{tabular}

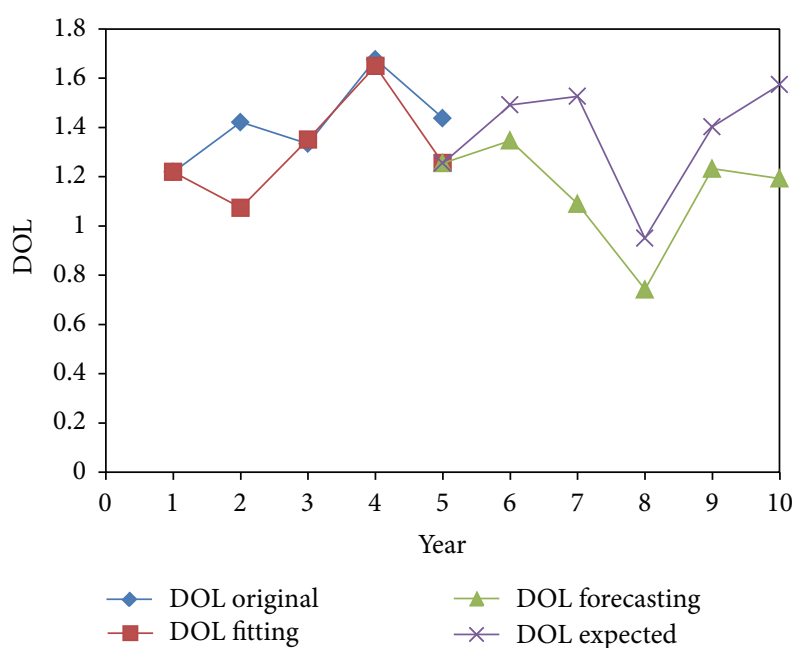

FIGURE 3: Original, fitting, one path forecasting, and expected values of DOL after 500 simulations.

Grey relational (relevance) analysis of $\mathrm{GM}(1,6)$ for one path of simulation is represented by Table 17.

According to Table 17, we obtain the simulated rank order of relevancy of the influencing variables over time as follows:

$$
\begin{aligned}
& \text { Year 1: } X_{4}>X_{3}>X_{2}>X_{5}>X_{1}>X_{6} . \\
& \text { Year 2: } X_{3}>X_{5}>X_{1}>X_{4}>X_{6}>X_{2} . \\
& \text { Year 3: } X_{2}>X_{1}>X_{3}>X_{4}>X_{5}>X_{6} . \\
& \text { Year 4: }\left(X_{1}=X_{6}\right)>X_{5}>X_{2}>X_{3}>X_{4} . \\
& \text { Year 5: } X_{5}>X_{3}>X_{6}>X_{1}>X_{2}>X_{4} .
\end{aligned}
$$

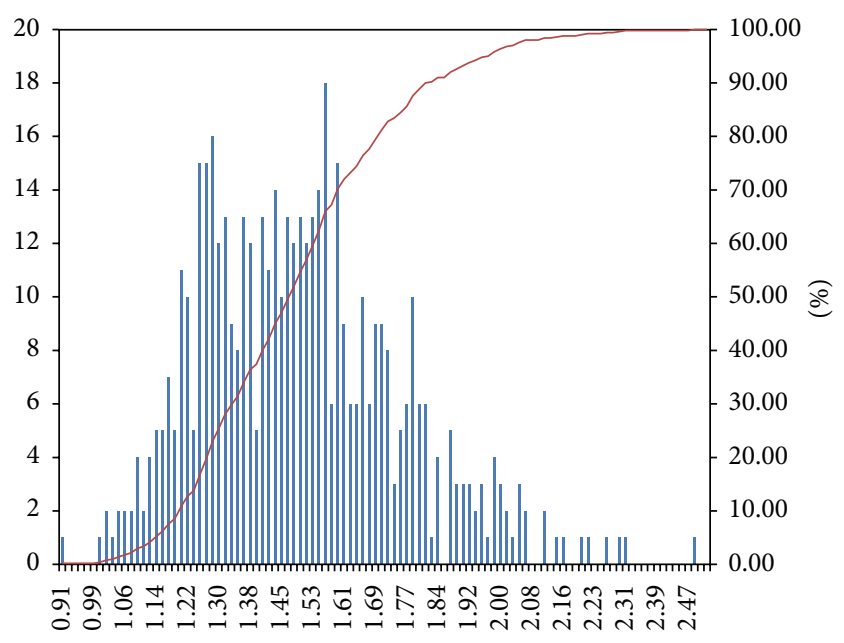

FIGURE 4: Distribution of forecasted DOL for the 6 th year.

According to aggregated values, we obtain the final simulated rank order of relevancy of the influencing variables as follows: $X_{3}>X_{5}>X_{2}>X_{1}>X_{4}>X_{6}$.

Since 500 simulations are performed, we obtain the correlation matrix as in Table 18.

According to Table 18, we obtain the expected rank order of relevancy of the influencing variables over time and final expected rank order as follows:

$$
\begin{aligned}
& \text { Year 1: } X_{3}>X_{2}>X_{4}>X_{1}>X_{6}>X_{5} . \\
& \text { Year 2: } X_{3}>X_{5}>X_{6}>X_{4}>X_{1}>X_{2} . \\
& \text { Year 3: } X_{2}>X_{3}>X_{1}>X_{4}>X_{5}>X_{6} .
\end{aligned}
$$


TABLE 15: Sum of the major and influencing sequence variables for $s=1$.

\begin{tabular}{lccccc}
\hline DOL $(k)$ & 1.346 & 1.089 & 0.742 & 1.232 & 1.192 \\
\hline$X_{1}(k)$ & 100000 & 105000 & 97000 & 100000 & 110000 \\
\hline$X_{2}(k)$ & 1600000 & 1800000 & 1500000 & 1500000 & 2000000 \\
\hline$X_{3}(k)$ & 13040642 & 12152559 & 13638024 & 9801869 & 14228955 \\
\hline$X_{4}(k)$ & 7156388 & 9274793 & 8805646 & 340 & 10546252 \\
\hline$X_{5}(k)$ & 330 & 330 & 340 & 95 & 340 \\
\hline$X_{6}(k)$ & 86 & 90 & 24041102 & 26857208 & 93 \\
\hline Sum & 21897447 & 23332773 & 26885641 \\
\hline
\end{tabular}

TABLE 16: Equalized values of the major and influencing sequence variables for $s=1$.

\begin{tabular}{lccccc}
\hline $\mathrm{DOL}^{\prime}(k)$ & $6.15 E-08$ & $4.67 E-08$ & $3.09 E-08$ & $4.59 E-08$ & $4.43 E-08$ \\
\hline$X_{1}^{\prime}(k)$ & 0.004567 & 0.0045 & 0.004035 & 0.003723 & 0.004091 \\
\hline$X_{2}^{\prime}(k)$ & 0.073068 & 0.077145 & 0.062393 & 0.063298 & 0.074389 \\
\hline$X_{3}^{\prime}(k)$ & 0.595533 & 0.520836 & 0.567279 & 0.568001 & 0.52924 \\
\hline$X_{4}^{\prime}(k)$ & 0.326814 & 0.397501 & 0.366275 & 0.364962 & 0.392263 \\
\hline$X_{5}^{\prime}(k)$ & $1.51 E-05$ & $1.41 E-05$ & $1.41 E-05$ & $1.27 E-05$ & $3.26 E-05$ \\
\hline$X_{6}^{\prime}(k)$ & $3.93 E-06$ & $3.86 E-06$ & $3.83 E-06$ & $3.16 E-06$ & $36-06$ \\
\hline
\end{tabular}

TABLE 17: Correlation matrix for $s=1$

\begin{tabular}{lcccccc}
\hline $\begin{array}{l}\text { DOL }(k) / X_{j} \\
\theta=0.5\end{array}$ & DOL(1) & DOL $(2)$ & DOL(3) & DOL $(4)$ & DOL(5) & Aggregated value \\
\hline$X_{1}$ & 0.876886 & 0.885498 & 0.950716 & 1 & 0.94227 & 0.931074 \\
\hline$X_{2}$ & 0.904383 & 0.87252 & 1 & 0.99112 & 0.893805 & 0.932366 \\
\hline$X_{3}$ & 0.916382 & 1 & 0.946311 & 0.945523 & 0.989839 & 0.959611 \\
\hline$X_{4}$ & 1 & 0.881448 & 0.930161 & 0.932326 & 0.889259 & 0.926639 \\
\hline$X_{5}$ & 0.893087 & 0.930804 & 0.930155 & 0.999411 & 0.950691 \\
\hline$X_{6}$ & 0.871197 & 0.879595 & 0.881844 & 1 & 0.944697 & 0.915467 \\
\hline
\end{tabular}

TABLE 18: Expected correlation matrix obtained after 500 simulations.

\begin{tabular}{lcccccc}
\hline $\begin{array}{l}\mathrm{DOL}(k) / X_{j} \\
\theta=0.5\end{array}$ & DOL(1) & DOL(2) & DOL(3) & DOL(4) & DOL(5) & Aggregated value \\
\hline$X_{1}$ & 0.912041 & 0.921771 & 0.925088 & 0.925480 & 0.939693 & 0.924814 \\
\hline$X_{2}$ & 0.928070 & 0.896937 & 0.957765 & 0.913864 & 0.876159 & 0.914559 \\
\hline$X_{3}$ & 0.934076 & 0.940820 & 0.935899 & 0.950123 & 0.953475 & 0.942879 \\
\hline$X_{4}$ & 0.922037 & 0.922130 & 0.911800 & 0.901827 & 0.905551 & 0.912669 \\
\hline$X_{5}$ & 0.890792 & 0.938745 & 0.870543 & 0.895710 & 0.958414 & 0.910841 \\
\hline
\end{tabular}

Year 4: $X_{3}>X_{6}>X_{1}>X_{2}>X_{4}>X_{5}$.

Year 5: $X_{5}>X_{3}>X_{1}>X_{6}>X_{4}>X_{2}$.

Final: $X_{3}>X_{1}>X_{2}>X_{4}>X_{6}>X_{5}$.

If we compare the final rank order of relevancy of the influencing variables obtained by observation to the final expected rank order of influencing variables obtained by simulation, it can be seen that the revenues retain the greatest relevance.
Level of relevancy of the influencing variable related to working days is significantly changed from the second level in the past to the sixth in the future. Influencing variable related to the production rate is increased its relevance from the fourth level in the past to the second in the future, while the rest variables retain approximately the same level of relevancy.

Key information obtained from the values of DOL can be summarized in Table 19. 
TABLE 19: DOL's indications.

\begin{tabular}{lcc}
\hline Parameter & High & Low \\
\hline $\begin{array}{l}\text { Variable costs (revenues } \\
\text { and fixed costs are fixed) }\end{array}$ & High & Low \\
\hline $\begin{array}{l}\text { Fixed costs (revenues and } \\
\text { variable costs are fixed) }\end{array}$ & Low & High \\
\hline $\begin{array}{l}\text { Revenues up (variable and } \\
\text { fixed costs are fixed) }\end{array}$ & Greater profits & Lower profits \\
\hline $\begin{array}{l}\text { Revenues down (variable } \\
\text { and fixed costs are fixed) }\end{array}$ & Greater losses & Lower losses \\
\hline
\end{tabular}

From Table 19, we can see why it matters if value of DOL is high or low. When DOL is high, a change in revenues results in large change in profit or loss. On the other hand, when DOL is low, a change in revenues results in small change in profit or loss.

\section{Conclusion}

Multivariable grey model is used to establish the sequence time response formula which defines the relationship between ore production rate, fixed costs, revenues, production costs, working days, and degree of use of production capacity, as input variables, and Degree of Operating Leverage as indicator of operational efficiency of an existing underground mine. The management of the company obtains the aggregated information vector which sublimates the following important indicators: forecasting model, relative percentage error of forecasting model, average relative percentage error of forecasting model, the grey relational coefficient between inputs and output for defined time interval, and aggregated grey relational coefficient between inputs and output.

Large capital intensive projects, such as those in the mineral resource industry, are often associated with diverse sources of both endogenous and exogenous uncertainties. These uncertainties can greatly influence the operational efficiency. Having the ability to plan for these uncertainties is increasingly recognized as critical to long-term mining company success. To decrease uncertainty of future values of the operational efficiency we use expert's knowledge and simulation processes to find future values of input variables affecting them. Estimation of future revenues is based on the application of mean reversion process, normal and uniform distribution. Geometric Brownian motion is used to define future values of production costs. Values of ore production rate, fixed costs, working days, and degree of use of production capacity are estimated by expert's knowledge. Simulation results in the average or expected value of Degree of Operating Leverage for every year of defined time horizon. Degree of Operating Leverage is very important indicator to the management of the mining company because it can be used as a good base for Cost-Volume-Profit analysis.

The limitation of the developed model is related to the expert's estimation of the production rate, fixed costs, working days, and degree of use of production capacity as deterministic or crisp values. In order to overcome this problem, we concern the possibility of application of interval or fuzzy numbers as a way to decrease uncertainty of these variables. It increases the complexity of the calculation but makes the model much more realistic. Another one approach of further exploration can be directed to developing submodels finding the future states of these variables and incorporation of them into main forecasting model.

\section{Conflict of Interests}

The authors declare that there is no conflict of interests regarding the publication of this paper.

\section{References}

[1] S. Briciu, S. Capusneanu, I. Sorina (Rakos) Boca, and D. Ioan Topor, "Cost analysis and reporting the performances of companies in the mining industry," in Proceedings of the 6th International Conference on Applied Economics, Business and Development (AEBD '14), pp. 51-56, Lisbon, Portugal, October 2014, http://www.wseas.us/e-library/conferences/2014/Lisbon/ AEBD/AEBD-07.pdf.

[2] X. Zhao, L. Li, and X.-S. Zhang, "Analysis of operating efficiency of Chinese Coal Mining industry," in Proceedings of the IEEE 18th International Conference on Industrial Engineering and Engineering Management (IE\&EM '11), Part 2, pp. 889-893, Changchun, China, September 2011.

[3] Z.-W. Li, L.-J. Wang, and D.-P. Wang, "Performance evaluation of coal mine listed company based on factor analysis," China Mining, vol. 17, no. 2, pp. 10-13, 2008.

[4] F. A. Khrisat, A. Y. Khasawneh, and A. A. Al-Waked, "Managerial and operational efficiency valuation of privatized firms: case of Jordan mining sector," European Journal of Economics, Finance and Administrative Sciences, no. 49, pp. 56-70, 2012.

[5] O. A. Akinboade, E. C. Kinfack, M. P. Mokwena, and W. L. Kumo, "Estimating profit efficiency in the South African mining sector using stochastic frontier approach," Problems and Perspectives in Management, vol. 8, no. 1, pp. 136-142, 2010.

[6] C. Musingwini and R. C. A. Minnitt, "Ranking the efficiency of selected platinum mining methods using the analytic hierarchy process (AHP)," in Proceedings of the 3rd International Platinum Conference 'Platinum in Transformation', pp. 319-326, The Southern African Institute of Mining and Metallurgy, Johannesburg, South Africa, October 2008.

[7] S. Nel, M. S. Kizil, and P. Knights, "Improving truck-shovel matching," in Proceedings of the 35th APCOM Symposium, pp. 381-391, Wollongong, Australia, September 2011.

[8] J. L. Deng, "Introduction to grey system," The Journal of Grey System, vol. 1, no. 1, pp. 1-24, 1989.

[9] E. Kayacan, B. Ulutas, and O. Kaynak, "Grey system theorybased models in time series prediction," Expert Systems with Applications, vol. 37, no. 2, pp. 1784-1789, 2010.

[10] Y. M. Chang, M. L. You, J. M. Tseng, C. P. Lin, and C. M. Shu, "Applying grey system theory to rank the influence factors in the benzene and methanol mixtures of fire and explosion hazard evaluation," in Proceedings of the 37th Annual Conference on Thermal Analysis (NATAS '09), Paper no. 25-3873565, Lubbock, Tex, USA, September 2009. 
[11] H. Hui, F. Li, and Y. Shi, "An optimal multi-variable grey model for logistics demand forecast," International Journal of Innovative Computing, Information and Control, vol. 9, no. 7, pp. 29072918, 2013.

[12] K. Tang, F. Wang, J. Liu, P. Jia, and J. Liu, "Water vapor permeability of leathers by grey system theory," Reviews on Advanced Materials Science, vol. 33, no. 4, pp. 373-382, 2013.

[13] Y.-H. Lin, P.-C. Lee, and T.-P. Chang, "Adaptive and high-precision grey forecasting model," Expert Systems with Applications, vol. 36, no. 6, pp. 9658-9662, 2009.

[14] Y.-T. Lee and C.-S. Chiu, "Skin physiology analysis via grey $\mathrm{GM}(1, \mathrm{~N})$ and $\mathrm{GM}(0, \mathrm{~N})$ model," International Journal of BioScience and Bio-Technology, vol. 1, no. 1, pp. 25-36, 2009.

[15] Y. Wang, G. Zhang, K. S. Moon, and J. W. Sutherland, "Compensation for the thermal error of a multi-axis machining center," Journal of Materials Processing Technology, vol. 75, no. 1-3, pp. 45-53, 1998.

[16] X. Wang, "Grey relational analysis of teaching skills and learning results of aerobics," Advances in Information Sciences and Service Sciences, vol. 4, no. 10, pp. 321-328, 2012.

[17] J. J. Weygandt, P. D. Kimmel, and D. E. Kieso, Managerial Accounting: Tools for Business Decision Marketing, John Wiley \& Sons, 5th edition, 2010.

[18] H. Kiymaz and R. Hodgin, "Enhancing clarity and completeness of basic financial text treatments on operating leverage," Journal of Economics and Finance Education, vol. 2, no. 1, pp. 35-45, 2003.

[19] F. H. M. Sßnchez, Y. C. Vargas, and M. P. Cardozo, "Numerical comparison of pricing of european call options for mean reverting processes," International Journal of Research and Reviews in Applied Sciences, vol. 14, no. 2, pp. 358-395, 2013.

[20] J. Janczura, S. Orzeł, and A. Wyłomańska, "Subordinated $\alpha$ stable Ornstein-Uhlenbeck process as a tool for financial data description," Physica A: Statistical Mechanics and Its Applications, vol. 390, no. 23-24, pp. 4379-4387, 2011.

[21] G. S. Ladde and M. Sambandham, Stochastic Versus Deterministic Systems of Differential Equations, Marcel Dekker, New York, NY, USA, 2004. 


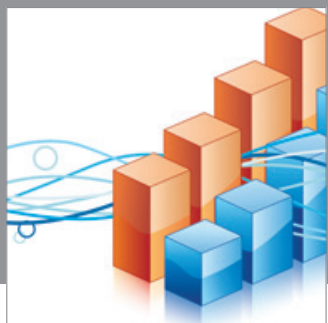

Advances in

Operations Research

mansans

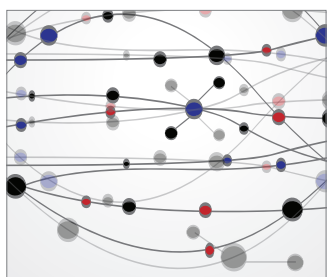

The Scientific World Journal
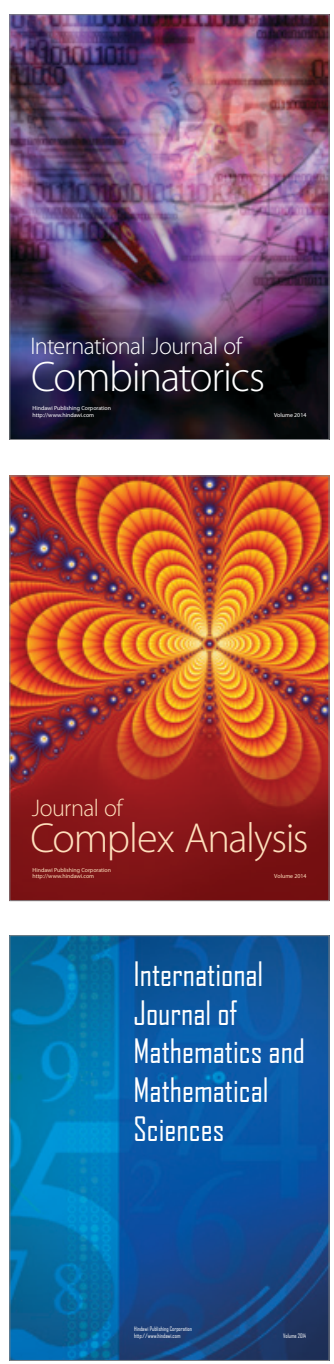
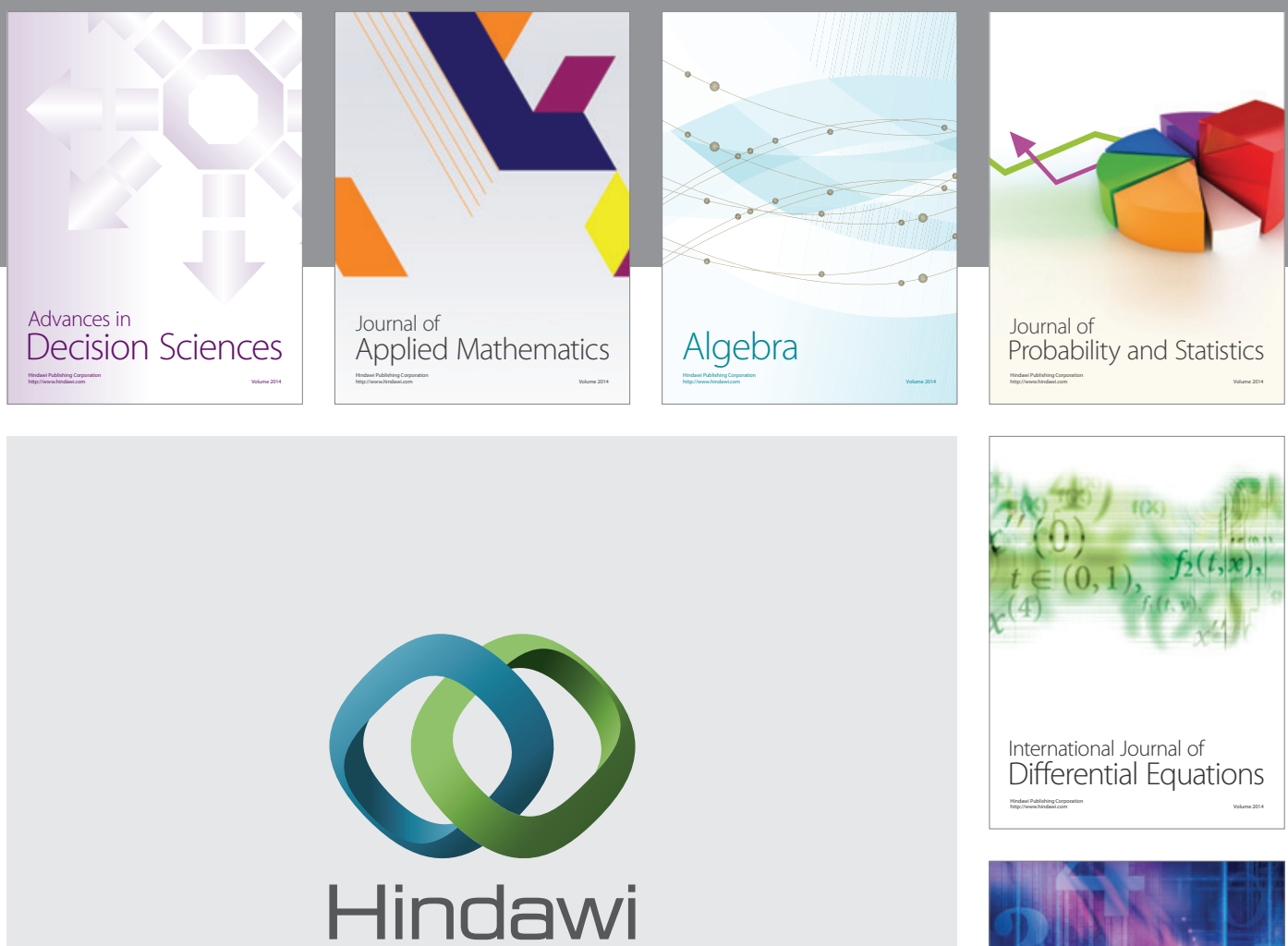

Submit your manuscripts at http://www.hindawi.com
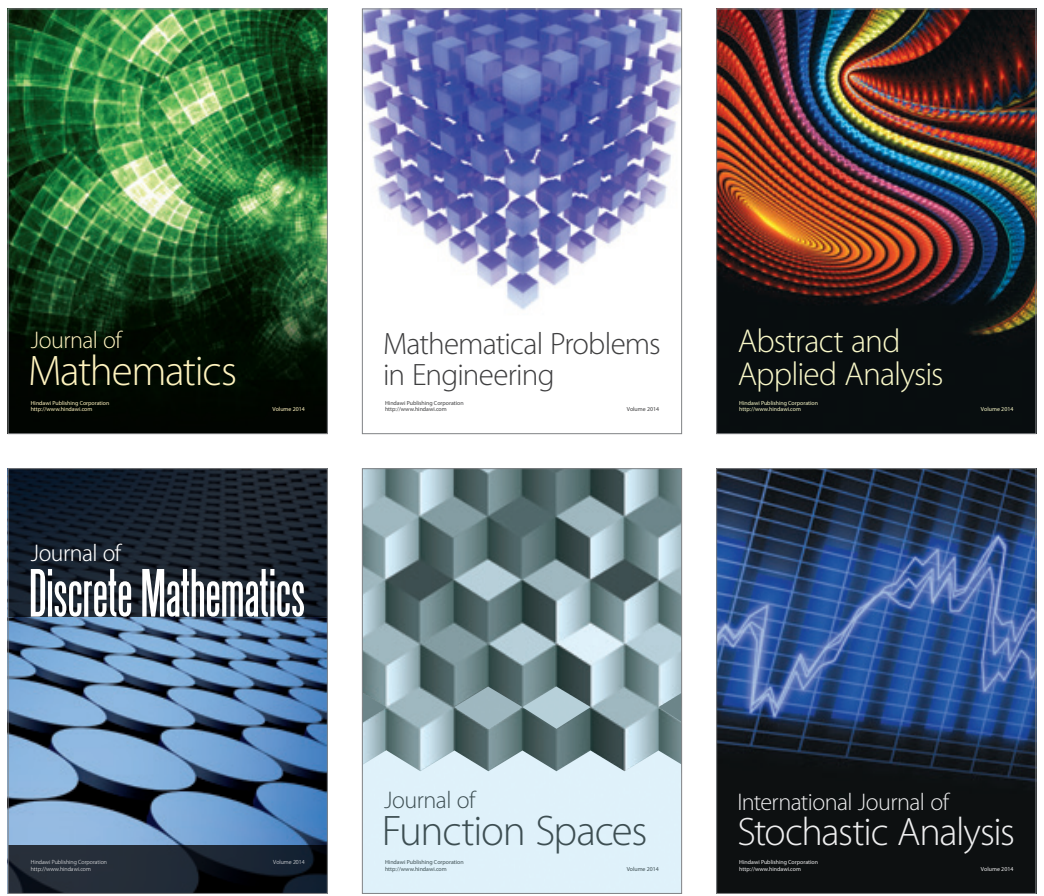

Journal of

Function Spaces

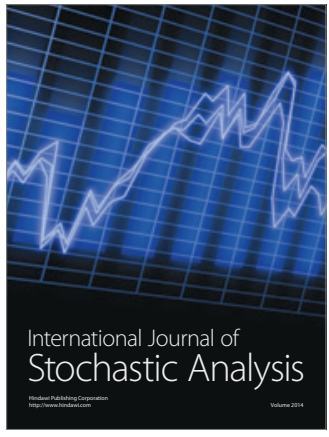

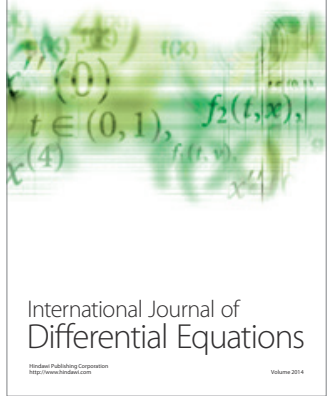
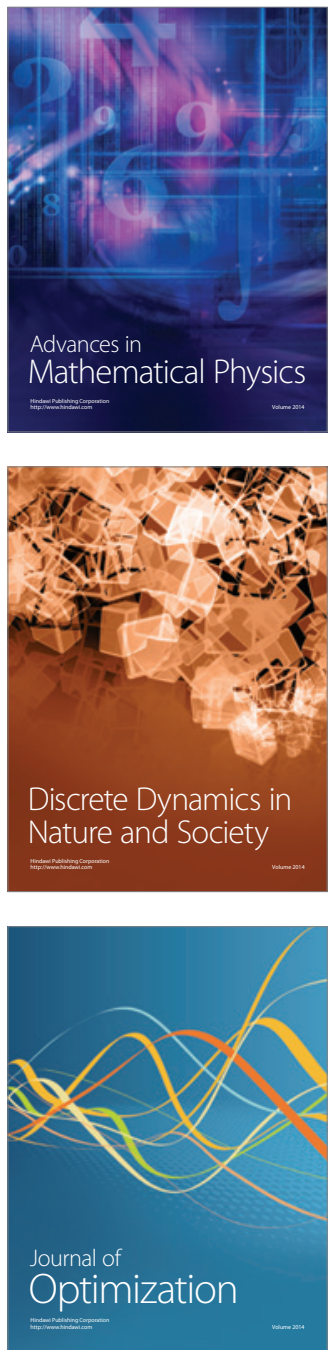